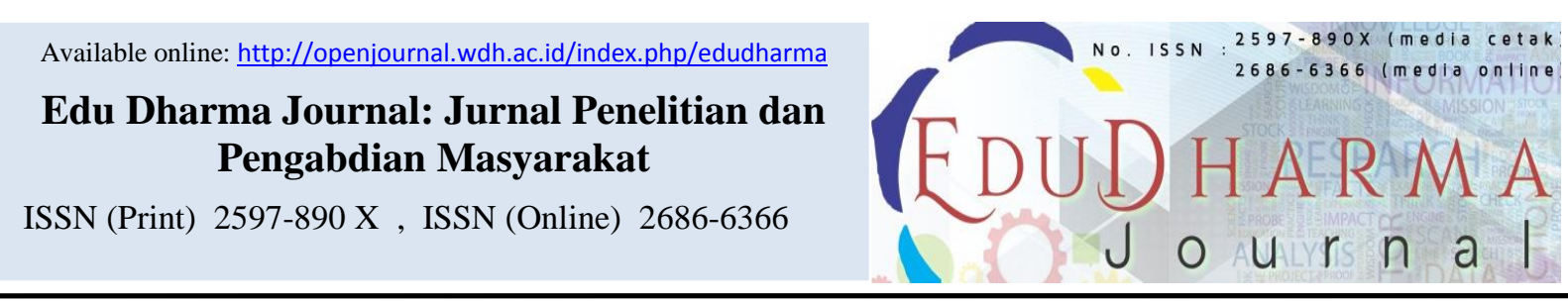

\title{
HUBUNGAN KELULUSAN AKREDITASI RUMAH SAKIT DENGAN KEPUASAN PASIEN RAWAT INAP RSUD TAMANSARI PROVINSI DKI JAKARTA
}

\section{Riska Edwi Meilia}

STIKes Kharisma Persada Tangerang, Jl. Pajajaran No. 1 Pamulang, Tangerang Selatan 15417, Indonesia., RSUD Tamansari Provinsi DKI Jakarta

\begin{tabular}{|c|c|}
\hline ARTICLE INFORMATION & $A B S T R A C T$ \\
\hline $\begin{array}{l}\text { Name : Riska Edwi Meilia } \\
\text { Email: riskaedwi@ gmail.com }\end{array}$ & $\begin{array}{l}\text { The authority is the statement to the quality of the hospitals in } \\
\text { accordance with standard and has been declared the hospital to meet the } \\
\text { standard of accreditation The quality of good service can lead to } \\
\text { increased. customer satisfactionThe quality of can provide the } \\
\text { motivation to the patient as a customer to establish a good relationship }\end{array}$ \\
\hline $\begin{array}{l}\text { Keywords: } \\
\text { Hospital accrediting_1 } \\
\text { Patient satisfaction_2 } \\
\text { Standard of Accreditation_3 }\end{array}$ & $\begin{array}{l}\text { with the hospital providing service. Satisfaction is benchmark a decision } \\
\text { the purchase in which to come.Improve the quality of and performance } \\
\text { services have already should be tried sustainably. The independent or } \\
\text { outsiders who pass judgment needed to improve the quality of a default } \\
\text { judgment appointed with authorities. The purpose of this research to see } \\
\text { if there a connection graduation accrediting a hospital against } \\
\text { satisfaction inpatients at RSUD Tamansari jakarta on 2019. The kind of } \\
\text { research in this research was used the cross sectional. quantitativeThe } \\
\text { research was conducted in the hospital in-patient tamansari jakarta.The } \\
\text { research was conducted in the february year } 2019 . \text { The number of } \\
\text { samples from } 79 \text { in-patient. The results of the study known from } \\
79 \text { responden stating satisfied with the service after } 51 \text { pass accreditation } \\
\text { ( } 81 \% \text { ) } 13 \text { while respondents said are not satisfied because indicators } \\
\text { to the authority did not pass. Statistical tests said there was a correlation } \\
\text { with the p value = 0.001 ); } 0,05 \text { \& it, so which a conclusion can be } \\
\text { taken is there was a correlation between passing accrediting a hospital } \\
\text { with satisfaction inpatients tamansari city hospital. Suggestions from the } \\
\text { results of this study are expected the hospital can be committed in } \\
\text { providing excellent service to patients in accord with standards. hospital } \\
\text { accreditation. }\end{array}$ \\
\hline $\begin{array}{l}\text { Kata Kunci: } \\
\text { Akreditasi RS_1 } \\
\text { Kepuasan Pasien_2 } \\
\text { Standar Akreditasi_3 }\end{array}$ & $\begin{array}{l}\text { A B S T R A K } \\
\text { Akreditasi adalah pernyataan untuk kualitas pelayanan yang diberikan } \\
\text { Rumah Sakit yang sesuai dengan standar serta telah dinyatakan Rumah } \\
\text { Sakit tersebut telah memenuhi Standar Akreditasi. Kualitas pelayanan } \\
\text { yang baik dapat menyebabkan kepuasan pelanggan meningkat. Kualitas } \\
\text { dapat memberikan motivasi kepada pasien sebagai pelanggan untuk } \\
\text { menjalin hubungan yang baik dengan Rumah sakit yang memberikan } \\
\text { pelayanan. Kepuasan merupakan tolak ukur sebuah keputusan } \\
\text { pembelian dimasa yang akan datang. Meningkatkan kualitas serta } \\
\text { kinerja pelayanan sudah seyogyanya diupayakan secara berkelanjutan. } \\
\text { Pihak independen atau pihak luar yang memberikan penilaian } \\
\text { dibutuhkan untuk peningkatan kualitas dengan standar penilaian yang }\end{array}$ \\
\hline
\end{tabular}




\begin{tabular}{|l|l|}
\hline \multirow{1}{*}{$\begin{array}{l}\text { telah ditentukan pihak berwenang. Tujuan dari penelitian ini untuk } \\
\text { mengetahui apakah ada hubungan kelulusan akreditasi rumah sakit } \\
\text { terhadap kepuasan Pasien Rawat Inap RSUD Tamansari Provinsi DKI } \\
\text { Jakarta tahun 2019. Jenis penelitian dalam penelitian ini adalah } \\
\text { kuantitatif menggunakan pendekatan cross sectional. Penelitian ini } \\
\text { dilakukan di Ruang Rawat Inap RSUD Tamansari Provinsi DKI Jakarta. } \\
\text { Penelitian ini dilakukan pada bulan Febuari tahun 2019. Jumlah sampel } \\
\text { sebanyak 79 pasien rawat inap Hasil penelitian diketahui dari } \\
\text { 79responden yang menyatakan puas atas pelayanan pasca lulus } \\
\text { akreditasi yaitu 51 (81\%) sedangkan dari 13 responden yang } \\
\text { menyatakan tidak puas karena indikator dalam akreditasi tidak lulus. Uji } \\
\text { statistik menyatakan ada hubungan dengan nilai P value }=0.001)<0,05, \\
\text { maka Kesimpulan yang dapat diambil adalah ada hubungan antara } \\
\text { kelulusan akreditasi rumah sakit dengan kepuasan Pasien Rawat Inap } \\
\text { RSUD Tamansari Provinsi DKI Jakarta Saran dari hasil penelitian ini } \\
\text { diharapkan Rumah sakit dapat berkomitmen memberikan pelayanan } \\
\text { prima kepada pasien dengan memenuhi standar akreditasi RS. }\end{array}$} \\
\hline
\end{tabular}




\section{PENDAHULUAN}

Sebagai sebuah institusi penyedia pelayanan kesehatan, Rurnah sakit senantiasa mengikuti perkembangan teknologi di di zama semakin modern ini, sehingga antar Rumah Sakit saling berkompetisi dalam menciptakan mutu atau kualitas pelayanan terbaik bagi pelanggan (Azwar, 2010; Pratiwi, 2015).

Berdasarkan data Kementrian Kesehatan Republik Indonesia, pertambahan jumlah ruinah sakit terlihat begitu pesat diketahui di data tahun 2015, Di Indonesia terdapat sejumlah 2490 unit Rumah Sakit,dan meningkat pada tahun 2017 terdaftar ada 2773 unit Rumah Sakit, hal ini dapat disimpulkan bahwa ada $21 \%$ kenaikan jumlah rumah sakit dalam kurun waktu 2 tahun. (Kemenkes Rl, 2018). Undang-Undang Republik Indonesia No. 44 Tahun 2009 tentang Rumah Sakit menerangkan bahwa Rumah sakit mempunyai kewajiban memberikan pelayanan kesehatan yang aman, berkualitas tinggi, antidiskriminasi, dan efektif dengan mengutamakan kepentingan pelanggan atau pasiennya sesuai dengan standar pelayanan rumah sakit.

Meningkatkan Kualitas RS dan kinerja pelayanan harus diupayakan secara berkelanjutan, Pihak independen atau pihak luar yang memberikan penilaian dibutuhkan untuk peningkatan kualitas dengan standar penilaian yang telah ditentukan pihak berwenang.yaitu melalui mekanisme akreditasi demi terjaminnya perbaikan kualitas pelayanan, peningkatan kinerja dilaksanakan ber kesinambungan (Sutoto, 2017). Dalam Peraturan Menteri Kesehatan Republik Indonesia Nomor 34 Tahun 2017 tentang Akreditasi Rumah Sakit bahwa setiap Rumah Sakit wajib melakukan penilaian akreditasi pengulangan setiap 3 tahun. Akreditasi adalah pernyataan untuk kualitas pelayanan yang diberikan Rumah Sakit yang sesuai dengan standar serta telah dinyatakan Rumah Sakit tersebut telah memenuhi Standar Akreditasi. (Permenkes Rl, 2017)

RSUD Tamansari adalah Rurnah Sakit tipe D milik pemerintah provinsi DKI Jakarta yang diresmikan pada tahun 2016. Seiring dengan bertambahnya pelayanan spesialis di RSUD Tamansari, maka jumlah kunjungan yang terus meningkat dari 232 pasien (2016), 715 pasien (2017) dan 1016 pasien (2018). Semakin banyak pasien berobat, maka akan semakin meningkat pandangan pasien terhadap mutu atau kualitas 
pelayanan Rumah Sakit. Pasien rawat inap adalah pasien yang merasakan pelayanan secara inenyeluruh lebih dari 24 jam (Permenkes 69/20 14).

RSUD Tamansari sudah mendapatkan pengakuan atas kualitasnya dengan lulus akreditasi rnadya dalam SNARS Edisi I tahun 2018) dan akan mempersiapkan verifikasi pada bulan Desember 2018.

Kepuasan pelanggan meningkat seiring dengan kualitas pelayanan yang diberikan juga baik. Kualitas memberikan suatu dorongan kepada pelanggan untuk menjalin ikatan hubungan yang kuat dengan perusahaan yang memberikan pelayanan. Kepuasan jga dapat merupakan tolak ukur keputusan pembelian dimasa yang akan datang (Pratiwi, 2019; At mawati dan Wahyudin, 2007).

Berdasarkan survei data pendahuluan bulan desember tahun 2018, terdapat 5 pasien menyatakan tidak puas dengan pelayanan RSUD Tainansari. Adapun data kepuasan pasien dari tahun 2016 dan 2017 mengalami penurunan dari $78 \%$ menjadi $76 \%$. Adanya keluhan atas ketidakpuasan pasien, membuat peneliti melakukan untuk mengetahui kepuasan pasien rawat inap RSUD Tamansari yang memiliki status akreditasi madya dari
KARS dengan pendekatan teori dimensi mutu pelayanan. Berdasarkan uraian dalam latar belakang, Peneliti merumuskan masalah penelitian menjadi Adakah Hubungan Kelulusan Akreditasi Rumah Sakit dengan Kepuasan Pasien Rawat Inap RSUD Tamansari Provinsi DK1 Jakarta Tahun 2019”.

\section{METODE PENELITIAN}

Jenis Penelitian dalam penelitian ini adalah kuantitatif dengan menggunakan pendekatan crosssectional. Lokasi penelitian di Ruang Rawat Inap RSUD Tamansari Provinsi DKI Jakarta. Penelitian dilaksanakan pada bulan Febuari tahun 2019.

Seluruh pasien rawat inap RSUD Tamansari Provinsi DKI Jakarta pada bulan Febuari 2019 sebanyak 79 pasien dijadikan sampel penelitian sesuai teknik total sampling. Adapun Pasien rawat inap dari penelitian ini sebagai syarat dalam kriteria inklusi, pengisian kuesioner bisa diwakilkan oleh keluarga pasien ( 1 pasien 1x mengisi kuesioner). Kriteria inklusi lainnya adalah Responden dapat berkomunikasi dan menulis dengan baik (dapat menggunakan bahasa Indonesia), bersedia mengisi informed consent sebgai syarat bersedia menjadi responden Sedangkan kriteria Eksklusi adalah pasien 
yang tidak dapat berkomunikasi dan menulis dengan baik dan atau tidak ada keluarga yg mampu mewakili, serta adanya gangguan jiwa ringan maupun berat. Data dikumpulkan dengan cara mengisi kuesioner yang berisi karakteristik responden yang terdiri dari umur, jenis kelamin, dan pendidikan. Penilaian kelulusan akreditasi dilihat dari dokumen akreditasi sedangkan kuesioner kepuasan pelanggan rawat inap menggunakan kuesioner penelitian yang mengacu pada indikator SERVQUAL. Analisa univariat dan bivariat menggunakan uji Chi square $\left(x^{2}\right)$ digunakan untuk Pengolahan dan analisa data.

\section{HASIL PENELITIAN}

\section{ANALISA UNIVARIAT}

\section{A. Gambaran Karakteristik Responden}

Tabel 1. Gambaran Karakteristik Pasien Rawat Inap RSUD Tamansari ( $\mathrm{n}=79)$

\begin{tabular}{|c|c|c|}
\hline $\begin{array}{c}\text { Karakteristik } \\
\text { Responden } \\
\end{array}$ & $\mathbf{f}$ & $\%$ \\
\hline \multicolumn{3}{|l|}{ Umur } \\
\hline 17-24 Tahun & 20 & 25,3 \\
\hline 25-34 Tahun & 29 & 36,7 \\
\hline 35-49 Tahun & 18 & 22,8 \\
\hline 50-64 Tahun & 7 & 8,9 \\
\hline$>65$ tahun & 5 & 6,3 \\
\hline Jumlah & 79 & 100 \\
\hline \multicolumn{3}{|l|}{ Jenis Kelamin } \\
\hline Perempuan & 49 & 62,0 \\
\hline Laki-laki & 30 & 38,0 \\
\hline Jumlah & 79 & 100 \\
\hline \multicolumn{3}{|l|}{ Status } \\
\hline Umum & 27 & 34,1 \\
\hline BPJS & 52 & 65,8 \\
\hline Lainnya & 0 & 0 \\
\hline Jumlah & 79 & 100 \\
\hline \multicolumn{3}{|l|}{ Lama dirawat } \\
\hline$<3$ hari & 19 & 24,1 \\
\hline 3-6 hari & 55 & 69,6 \\
\hline $7-15$ hari & 3 & 3,8 \\
\hline$>15$ hari & 2 & 2,5 \\
\hline Jumlah & 79 & 100 \\
\hline \multicolumn{3}{|l|}{ Pekerjaan } \\
\hline Pelajar/Mahasiswa & 18 & 22,8 \\
\hline TNI POLRI/ PNS & 2 & 2,5 \\
\hline Swasta & 14 & 17,7 \\
\hline Buruh & 10 & 12,7 \\
\hline Pedagang & 10 & 12,7 \\
\hline Tidak bekerja & 25 & 31,6 \\
\hline
\end{tabular}




\begin{tabular}{ccc}
\hline $\begin{array}{c}\text { Karakteristik } \\
\text { Responden }\end{array}$ & f & $\%$ \\
\hline Jumlah & $\mathbf{7 9}$ & $\mathbf{1 0 0 , 0}$ \\
\hline
\end{tabular}

Data yang didapat pada tabel 1 yaitu 79 responden yang paling banyak berusia 2534 tahun sebanyak 29 responden $(36,7 \%)$, data yang berjenis kelamin perempuan sebanyak 49 responden (62\%), data responden dengan status berobat yaitu pasien BPJS yaitu 52 responden $(65,8 \%)$ dengan paling banyak waktu rawat 3-6 hari, dan karakteristik prkrtjaan, mayoritas tidak bekerja yaitu 25 responden $(31,6 \%)$.

\section{B. Gambaran Kelulusan Akreditasi}

Akreditasi dilaksanakan oleh RSUD Tamansari pada bulan november 2018 dengan 15 kelompok kerja (pokja) dalam standar akreditasi RS (SNARS) Edisi 1. Adapun status kelulusannya terlihat dalam gambar 1

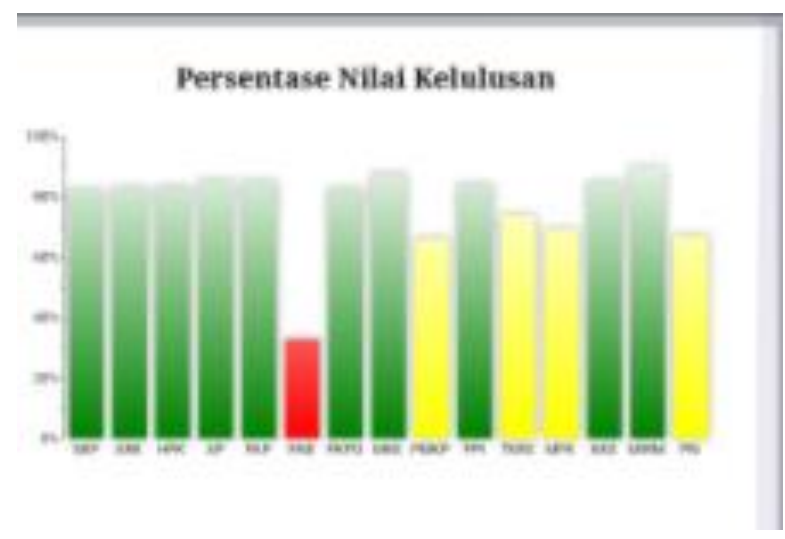

Gambar 1. Presentase Nilai Kelulusan

Dari gambar 1 terlihat bahwa ada 5 pokja yang masih dibawah standar kelulusan, yaitu pokja Peningkatan Mutu dan keselamatan pasien(PMKP), pokja Tata Kelola Rumah Sakit (TKRS), pokja Manajemen dan Fasilitas Keamanan (MFK), pokja Pelayanan Anestesi dan Bedah (PAB), dan program Nasional. Ada 10 pokja dari 15 pokja yang memenuhi standar kelulusan, maka RSUD Tamansari memperoleh status kelulusan "MADYA". Dalam penelitian ini, dikategorikan standar akreditasi sudah lulus dan belum lulus dengan mengkategorikan standar yang ada dala buku panduan SNARS Edisi 1 ada 79 indikator yang akan digunakan di pasien rawat inap . 
Diagram 1. Presentase nilai kelulusan akreditasi RSUD Tamansari

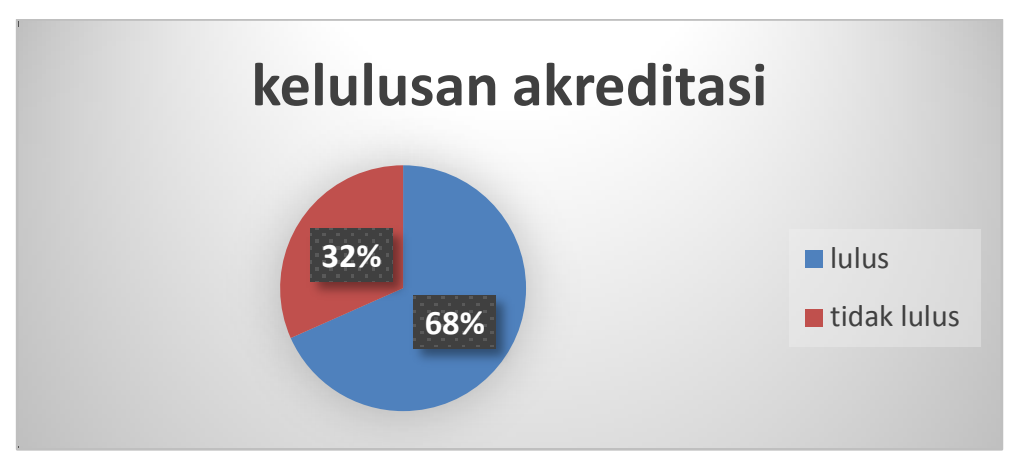

\section{Gambaran Kepuasan Pelanggan}

Diagram 2. Distribusi Kepuasan pasien rawat inap RSUD Tamansari $(\mathrm{n}=79)$

kepuasan pasien

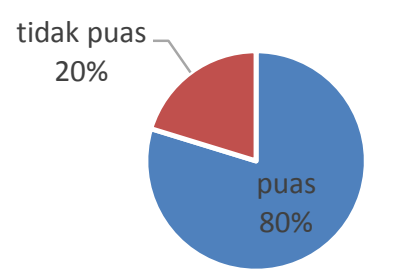

Berdasarkan Diagram 2 diketahui bahwa dari 79 responden pasien rawat inap, $80 \%$ puas (63 responden) terhadap layanan dan
20\% (16 responden) tidak puas. Gambaran kepuasan pasien dikategorikan menjadi dua yaitu puas dengan skor $\geq 80 \%$ dan tidak puas dengan skor $<80 \%$.

\section{ANALISA BIVARIAT}

Analisis bivariat bertujuan untuk menguji hubungan antara variabel kelulusan akreditasi dan kepuasan pasien. Analisis bivariat menggunakan uji Chi Square $\left(\mathrm{X}^{2}\right)$. Uji signifikan dilakukan dengan menggunakan batas kemaknaan alpha $(0,05)$ dan Confidence Interval (tingkat kepercayaan) 95\%. Hasil tabel silang antara kelulusan akreditasi dengan kepuasan pasien dan hasil uji Chi Square $\left(\mathrm{X}^{2}\right)$ diuraikan berikut ini: 
Tabel 2. Hubungan Kelulusan Akreditasi Rumah Sakit dengan Kepuasan Pasien Rawat Inap RSUD Tamansari Provinsi DKI Jakarta $(\mathrm{n}=79)$

\begin{tabular}{|c|c|c|c|c|c|c|c|c|}
\hline \multicolumn{9}{|c|}{ Kepuasan pasien } \\
\hline $\begin{array}{l}\text { Kelulusan } \\
\text { Akreditasi }\end{array}$ & \multicolumn{2}{|c|}{ Puas } & \multicolumn{2}{|c|}{ Tidak Puas } & \multicolumn{2}{|c|}{ Total } & \multirow[t]{2}{*}{$\begin{array}{c}\text { POR } \\
(95 \% \\
\text { CI }) \\
\end{array}$} & \multirow[t]{2}{*}{$\begin{array}{c}P \\
\text { Value }\end{array}$} \\
\hline & $\mathrm{n}$ & $\%$ & $\mathrm{~N}$ & $\%$ & $\mathrm{~N}$ & $\%$ & & \\
\hline Lulus & 51 & 81 & 3 & 19 & 54 & 100 & \multirow{3}{*}{$\begin{array}{c}9,96 \\
(2,54- \\
39,14)\end{array}$} & \multirow{3}{*}{0,001} \\
\hline Tidak Lulus & 12 & 19 & 13 & 81 & 25 & 100 & & \\
\hline Jumlah & 63 & 100 & 16 & 100 & 79 & 100 & & \\
\hline
\end{tabular}

Berdasarkan yang dogambarkan dalam tabel 2 antara kelulusan akreditasi dengan kepuasan pasien rawat inap diketahui dari 79 responden yang menyatakan puas atas pelayanan pasca lulus akreditasi yaitu 51 (81\%) sedangkan dari 13 responden yang menyatakan tidak puas karena indikator dalam akreditasi tidak lulus. Dengan menggunakan alpha $5 \%(0,05)$ dari hasil uji Chi Square didapatkan nilai $p$ value $0,001(<$ alpha $=$ 0,05) dengan demikian dapat disimpulkan bahwa Ho ditolak yang berarti adanya hubungan antara Kelulusan Akreditasi Rumah Sakit dengan Kepuasan Pasien Rawat Inap RSUD Tamansari Provinsi DKI Jakarta Tahun 2019. Dengan nilai POR $=9,98(95 \% \mathrm{CI}=2,53-39,16)$ yang berarti bahwa adanya peluang 10 kali lebih besar dengan indikator kelulusan akreditasi yang tidak lulus untuk pasien rawat inap tidak puas jika disandingkan dengan indikator lulus.

\section{PEMBAHASAN}

Akreditasi Rumah sakit adalah upaya perbaikan lebih baik sesuai dengan standar, sesuai dengan pendapat Yildiz (2014). Akreditasi rumah sakit dapat berdampak positif pada kualitas layanan perawatan yang diberikan kepada pasien dan menghasilkan kepuasan pasien. Standar akreditasi juga mendorong perubahan layanan dirumah sakit yang lebih berkualitas. Rumah sakit yang terakreditasi melakukan upaya peningkatan mutu layanan secara berkala serta dapat meningkatkan kepercayaan masyarakat. Kotler (2012) memberikan pandangan bahwa suatu proses dapat mengatur, menyeleksi dan menjelaskan informasi yang diterimanya yang selanjutnya tercipta gambaran bermakna. Persepsi adalah pandangan atau penerimaan secara langsung dari suatu proses dalam diri seseorang untuk mengetahui banyak hal melalui inderanya. (KBB,2015). Kotler menyatakan bahwa kepuasan adalah 
tingkatan perasaan yang dirasakan seseorang dalam menyatakan kesenjangan antara kinerja produk/jasa yang diharapkan dengan yang sudah diterima. Menurut Hawkins dan Lonney terdapat konsep inti diantara berbedanya cara mengukur kepuasan pelanggan,dengan ketidaksesuaian/kesesuaian harapan konsumen dengan kinerja yang dirasakan sebenarnya pada produk/jasa.

\section{KESIMPULAN}

Penelitian ini menghasilkan kesimpulan yaitu Hubungan Kelulusan Akreditasi Rumah Sakit dengan Kepuasan Pasien Rawat Inap RSUD Tamansari Provinsi DKI Jakarta Tahun 2019.

\section{DAFTAR PUSTAKA}

Atmawati, R dan M, Wahyudin. 2007. Analisis Pengaruh Kualitas Pelayanan Terhadap Kepuasan Konsumen Pada Matahari Departement Store Di Solo Grand Mall. Surakarta: Jurnal Daya Saing, Program MM-UMS

Azwar, S. 2010. Sikap Manusia Teori dan Pengukurannya. Yogyakarta: Pustaka Pelajar.

Direktorat Jendral Bina Upaya Kesehatan Kementerian Kesehatan RI. 2016.

Gibson, J.L., Ivancevich, J.M., Donnelly, J.H., Konopaske, R., Organizations: Behavior, 2012.
Structure, Processes. Fourteenth Edition. New York: McGraw-Hill.

Barnadi, D., Maulana, A., Hardani. Translated by S., Wardani. Jakarta: Penerbit Erlangga,.2007..

Handayani, R. 2012. Akreditasi Rumah Sakit, Pengakuan Atas Kualitas Layanan. Mutu Pelayanan Kesehatan

Kemenkes RI. 2015. Rencana Strategis Kementerian Kesehatan tahun 2015-2019. Jakarta

Kementerian Kesehatan RI

Kemenkes R.I. 2018. Profil Kesehatan Indonesia. Jakarta

Pratiwi, R.D., 2019. Hubungan Komunikasi Terapeutik Dan Caring Dengan Kepuasan Pasien Terhadap Perawat Ruang Rawat Inap Penyakit Dalam Rumah Sakit Umum Multazam Medika Bekasi Timur. Jurnal penelitian dan pengabdian masyarakat, 2(2), pp.1-22.

Peraturan Menteri Kesehatan RI nomor 34 tahun 2017 tentang Akreditasi Rumah Sakit.2017..

Sutoto. Perubahan Paradigma SNARS Edisi 1 untuk Asesor Internal. Workshop Para Pimpinan Rumah Sakit. Jakarta, 2017

Sutoto, Atmodjo, Luwiharsih, Lumenta ., Reksoprojo,, Martoatmodjo,, Atmatyah, M., Saleh J.T.2013. Pedoman Tata Laksana Survei Akreditasi Rumah Sakit. Jakarta

UU No 44 Tahun 2009. Tentang Rumah Sakit. Jakarta : Kementerian Kesehatan 